\title{
Effect of Temperature and Metal Ions on Degradation of Oxytetracycline in Different Matrices
}

\author{
Yingying Zhang1, Heqing Tang1* ${ }^{*}$ Qian Zhou ${ }^{2}$, Lihua Zhu ${ }^{2 *}$ \\ ${ }^{1}$ Key Laboratory of Catalysis and Materials Science of the State Ethnic Affairs Commission and \\ Ministry of Education, College of Chemistry and Material Science, South-Central University for Nationalities, \\ Wuhan, China \\ ${ }^{2}$ College of Chemistry and Chemical Engineering, Huazhong University of Science and Technology, Wuhan, \\ China \\ Email: ${ }^{*}$ tangheqing@mail.scuec.edu.cn, ${ }^{*}$ Ihzhu63@yahoo.com.cn
}

Received 24 April 2014; revised 21 May 2014; accepted 8 June 2014

Copyright (C) 2014 by authors and Scientific Research Publishing Inc.

This work is licensed under the Creative Commons Attribution International License (CC BY). http://creativecommons.org/licenses/by/4.0/

(c) (i) Open Access

\begin{abstract}
Composting is widely applied in animal manure treatment and reclamation. The degradation of organic pollutants during the composting treatment is attributed to two parallel processes: one is the bioprocess induced by the used microorganisms, and the other is the chemical process. In order to clarify the relative contribution of the chemical process to the compositing, in this paper, oxytetracycline (OTC) was chosen to study the degradation of tetracyclines (TCs) in water and chicken manure. It was observed that the degradation of OTC in water was much faster than that in chicken mature. At $40^{\circ} \mathrm{C}, 95 \%$ of $0 \mathrm{TC}$ in water could be removed in two days, while it took about one month in mature. By increasing the temperature to $50^{\circ} \mathrm{C}, 60^{\circ} \mathrm{C}$ and $70^{\circ} \mathrm{C}$, the required degradation time (with the degradation efficiency more than 95\%) was shortened to 22,13 and 9 days, respectively. This difference was caused by desorption hysteresis and irreversible fixation due to the formation of complexes of OTC with co-existed metal ions in the matrix. It was found that the coexisted $\mathrm{Ca}^{2+}, \mathrm{Zn}^{2+}$ and $\mathrm{Ni}^{2+}$ ions decreased the degradation of $\mathrm{OTC}$, whereas $\mathrm{Cu}^{2+}$ ions promoted the degradation of OTC.
\end{abstract}

\section{Keywords}

Oxytetracycline, Degradation, Water, Complex, Chicken Manure

${ }^{*}$ Corresponding authors.

How to cite this paper: Zhang, Y.Y., Tang, H.Q., Zhou, Q. and Zhu, L.H. (2014) Effect of Temperature and Metal lons on Degradation of Oxytetracycline in Different Matrices. Journal of Environmental Protection, 5, 672-680. 


\section{Introduction}

Tetracyclines (TCs) have made an enormous contribution to animal husbandry, for they are used as feed additives to prevent disease, and promote the growth and development of animals [1]. However, this antibiotic is absorbed poorly in animal bodies, and 70\% - 90\% of the intake OTC may be excreted by animals as parent compounds or metabolites and thus enter the environment through the application of manure to land as organic fertilizer or on pasture [2] [3]. It was reported that the amounts of antibiotics varied from trace level to 200 $\mathrm{mg} \cdot \mathrm{kg}^{-1}$ in animal waste [4]. The disposed OTC not only causes pollution of soil and water, but also poses an increasing potential risk to ecosystem safety and human health through the food chain [5].

Livestock farms often remove antibiotics by composting the animal waste before its applying on the soil as fertiliser, and this is a practical and economical option to reduce antibiotic concentrations in manure and thereby decrease environmental risks. Composting is a controlled aerobic process by which diverse groups of microorganisms decompose organic materials, producing stable compost [6]. A study by Van Dijk and Keukens showed that the concentration of sulfachlorpyrazine in poultry manure was decreased by $58 \%$ - $82 \%$ by a composting for 8 days [7]. Dolliver et al. evaluated three turkey manure composting treatments with different treatment conditions, and observed no marked difference in antibiotic degradation among the treatments [8]. To understand the influence of composting process and the components of compost on the degradation of TCs, Kim et al. carried out field- and in-lab-scale investigations, and also found no difference in antibiotic degradation among the treatments [9]. In a pilot scale experiment, Arikan and coworkers investigated the effect of manure pile construction on pile temperature profiles and on the fate of OTC and chlortetracycline (CTC), and found that more than 99\% reduction in CTC was achieved in all treatments at the end of the composting period (22 - 35 days) [10]. Wang and Yates examined the effects of manure moisture, temperature, and the presence of other antibiotics on the degradation kinetics of OTC in manure [11]. However, there has not much attention paid to the influence of substances that are already in chicken manure on antibiotics degradation until now. The coexisted organics and metal ions may interact with antibiotics and then influence the removal of TCs.

The behavior of antibiotics during composting is complicated, because they can be adsorbed and degraded by microbes, and chelate with metals or organics in the matrix. Kuhne et al. reported that TC was degraded faster in liquid pig manure under aerobic conditions than under anaerobic conditions [12]. Ratasuk et al. also observed that if the microbes were killed before composting, temperature was the main factor influencing the degradation of OTC, whereas pH and light had little influence on the degradation of OTC in pig manure [13]. Arikan et al. confirmed that the loss of extractable CTC and OTC residues was increased with incubation time and temperatures [14]. During the composting process, temperatures often exceed $40^{\circ} \mathrm{C}$ as a result of intense biological activity. In high temperature phase, the temperature of compost can be up to $60^{\circ} \mathrm{C}-70^{\circ} \mathrm{C}$, and this stage usually lasts seven days if no manual intervention [15]. Previous laboratory-scale composting studies showed that thermophilic temperatures and aerobic conditions increase antibiotic removal rates [1]. Increasing temperature resulted in much increased rate of the OTC hydrolysis [16]. Generally, TCs adsorbed strongly to manure solids, and this is often related to the coexisted divalent cations in manures [17]. The remove of antibiotics during composting could be divided into two parts: the direct degradation by assimilation of microbes and the decomposition by heat [18]. The objective of this study was to investigate the part of thermal chemical decomposition. Our research discussed the behaviors of OTC degradation under several composting temperatures and compared the differences of OTC degradation in the chicken manure and water (the structure of OTC is shown in Figure 1). Many metal ions in the manure could complex with OTC and influence the degradation of OTC. Hence, the effect of heavy metals on remove of OTC was studied.

\section{Materials and Methods}

\subsection{Chemicals and Analytical Procedure}

OTC with 99\% purity was bought from Aladdin (Shanghai, China). Acetonitrile and methanol (HPLC grade, Fisher, Pittsburgh, PA, USA) were used as mobile phase for HPLC detection. Citric acid, sodium ethylenediamine tetraacetate and disodium hydrogen phosphate dodecahydrate were used to extract OTC from chicken manure. All of these chemicals were analytical grade reagents from Sinopharm Chemical Reagent Co., Ltd (China). Solid phase extraction (SPE) tubes (HLB, $60 \mathrm{mg} / 3 \mathrm{~mL}$ ) were obtained from Waters (Brussels, Belgium). They were conditioned with $5 \mathrm{~mL}$ methanol followed by $5 \mathrm{~mL}$ of deionized water before used to purify the manure samples. 


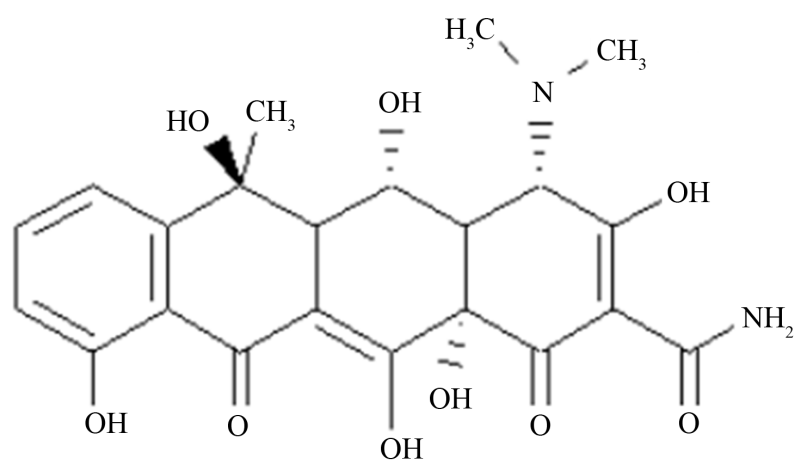

Figure 1. The chemical structure of OTC.

Chicken manure was obtained from a livestock farm in Hubei Province, China. The water content of the raw manure was $76.0 \%$, whilst its $\mathrm{pH}$ was 7.2 (using a manure-to-water ratio of 1:3 by mass). Fresh manure was analyzed by high performance liquid chromatography tandem mass spectrometry (HPLC-MS) and no OTC was detected. Prior to use in the experiments, it was kept in a $-20^{\circ} \mathrm{C}$ environment.

\subsection{Extraction and Analysis of OTC}

OTC in manure samples was extracted by EDTA-McIlvaine buffer solution. This buffer $(\mathrm{pH}=4.0)$ was prepared by dissolving $13.8 \mathrm{~g}$ disodium hydrogen phosphate dodecahydrate $\left(\mathrm{Na}_{2} \mathrm{HPO}_{4} \cdot 12 \mathrm{H}_{2} \mathrm{O}\right), 6.45 \mathrm{~g}$ citric acid $\left(\mathrm{C}_{6} \mathrm{H}_{8} \mathrm{O}_{7}\right)$ and $4.65 \mathrm{~g}$ disodium ethylenediamine tetraacetate $\left(\mathrm{Na}_{2}\right.$ EDTA) in $500 \mathrm{~mL}$ water. After Mcllvaine buffer-EDTA solution was added into manure, the solid-liquid mixture was vortexed for 1 min and then ultrasonicated for $10 \mathrm{~min}$ in an ultrasonic bath. The mixture was centrifuged, the supernatant was gathered and the solid was used to extract once more. The two supernatants were put together, into which was added one drop of $20 \%$ trichloroacetic acid solution to adjust $\mathrm{pH}$. The supernatants were filtered with $0.45 \mu \mathrm{m}$ syringe membrane filters. The filtrate was loaded on a conditioned HLB column to further purify it. The cartridge was rinsed with $5 \mathrm{~mL}$ of 5/95 (v/v) methanol-water solution. After the cartridge was vacuum dried for $10 \mathrm{~min}$, the analytes were eluted with $8 \mathrm{~mL}$ of 3/7 (v/v) methanol-ethyl acetate solution. The resultant eluate containing OTC was evaporated to dryness under a gentle stream of nitrogen at $40^{\circ} \mathrm{C}$ and the residue was redissolved in $1 \mathrm{~mL}$ of methanol. The reconstituted sample was analyzed by HPLC (Agilent 1260, Agilent, California, USA) with diode array detection. The analytical column was a C18 column (ZORBAX SB, $15 \mathrm{~cm} \times 0.46 \mathrm{~cm}, 5 \mu \mathrm{m}$ ) operated at room temperature. The chromatographic conditions were as follows: flow rate of $0.3 \mathrm{~mL} \cdot \mathrm{min}^{-1}$ with a mobile phase of $20 \%$ acetonitrile/10\% methanol/70\% 0.001 formic acid (v/v/v). The injection volume was $20 \mu \mathrm{L}$ and the detection was at $355 \mathrm{~nm}$.

\subsection{Data Analysis}

The OTC degradation kinetics in water was fitted with the simple first-order loss model:

$$
\mathrm{C}=\mathrm{C}_{0} \mathrm{e}^{-\mathrm{kt}}
$$

where $\mathrm{C}\left(\mathrm{mg} \cdot \mathrm{kg}^{-1}\right)$ is the concentration of the target compound at time $\mathrm{t}(\mathrm{day}), \mathrm{C}_{0}\left(\mathrm{mg} \cdot \mathrm{kg}^{-1}\right)$ is its initial concentration, and $\mathrm{k}$ is the degradation rate constant. The half life is calculated as $t_{1 / 2}=0.693 / \mathrm{k}$. For manure samples, the proportion of OTC available for degradation compared to the total amount in the system may decrease with time due to desorption hysteresis and irreversible fixation, because the manure contained many kinds of metal ions and organics and many of them would complex with OTC. Therefore, the OTC concentrations for each manure sample were fitted by an availability-adjusted first-order loss model describing exponential decay in manure. This model was introduced by Wang and Yates [11], which was supported by other reports [14] [19]. The availability-adjusted first order loss model introduces a parameter $\lambda$, which is the concentration ratio of the available target compound to the total remaining target compound in the system at initial time. This parameter $(\lambda)$ is assumed to be a function of time: $\lambda=\lambda_{0} \mathrm{e}^{-\mathrm{at}}$. Thus, Equation (3) was obtained after substituting $\lambda$ into Equation (2) and integration. 


$$
\begin{gathered}
-\frac{d C}{d t}=\mathrm{k}^{\prime} \lambda \mathrm{C} \\
\mathrm{C}=\mathrm{C}_{0} \mathrm{e}^{\left(-\mathrm{k}^{\prime} \lambda(1-\mathrm{e}-\mathrm{at}) / \mathrm{a}\right)}
\end{gathered}
$$

The availability-adjusted rate constant is denoted $\mathrm{k}^{\prime}\left(\mathrm{d}^{-1}\right)$ to distinguish from the rate constant $(\mathrm{k})$ associated with the simple first order loss model, and $\mathrm{k}^{\prime}\left(\mathrm{d}^{-1}\right)$ is the product of $\mathrm{k}$ and $\lambda$. Here, a $\left(\mathrm{d}^{-1}\right)$ represents an availability coefficient. The half-life may be expressed as:

$$
\mathrm{t}_{1 / 2}=-1 / \mathrm{a} \ln \left(1-0.693 \mathrm{a} / \mathrm{k}^{\prime}\right)
$$

\section{Degradation Experiments of OTC}

Experiments in solid substrate: Manure samples were spiked by adding of OTC solution (1000 $\left.\mathrm{mg} \cdot \mathrm{L}^{-1}\right)$ to make up nominal initial OTC concentrations of 10,25 and $100 \mathrm{mg} \cdot \mathrm{kg}^{-1}$ (dry weight). These concentrations were similar to that of OTC previously found in fresh manure from OTC-treated animals [10]. The initial water content was $79 \%$. After being sealed in a container, the spiked manure was put into a thermostatic oven for the degradation. At specified time intervals, a part of the samples were taken out for analyzing the content of OTC. During the experiment, a proper amount of water was added into the manure to keep the water contents be the same as the initial moisture content.

Experiments in liquid substrate: The degradation of OTC at an initial concentration of $10 \mathrm{mg} \cdot \mathrm{L}^{-1}$ was conducted in water. Prior to the experiment, the solution $\mathrm{pH}$ was adjusted to nearly neutral. At specified time intervals, a part of the samples were taken out for analyzing the content of OTC. In some cases, the OTC aqueous solution was spiked with metal ions $\left(\mathrm{Ca}^{2+}, \mathrm{Zn}^{2+}, \mathrm{Ni}^{2+}, \mathrm{Cu}^{2+}\right)$ at different concentrations.

\section{Results and Discussion}

\subsection{Extraction Recovery of OTC}

Using the extraction and HPLC conditions described above, the retention time for OTC was $7.6 \pm 0.1 \mathrm{~min}$, the calibration curves were linear with correlation coefficients $>0.99$ and method detection limit (MDL) of OTC in manure samples was $0.6 \mathrm{mg} \cdot \mathrm{kg}^{-1}$. The linearity ranges were $0.3-12 \mathrm{mg} \cdot \mathrm{L}^{-1}$ for water samples and $0.9-10$ $\mathrm{mg} \cdot \mathrm{L}^{-1}$ for manure samples. Recovery results for OTC were calculated as means of triplicate samples at four concentrations in water and manure. As shown in Table 1, the recoveries of OTC were about $85 \%$ from the manure and about $95 \%$ from water.

\subsection{Degradation of OTC at Different Temperatures}

Initial concentrations of OTC after mixing were approximately 100 , 25, and $10 \mathrm{mg} \cdot \mathrm{kg}^{-1}$, within the range of antibiotic concentrations found in animal manure [20]. The temperature during composting can be up to $70^{\circ} \mathrm{C}$, so $70^{\circ} \mathrm{C}$ was chosen as the maximum temperature in the experiments. The degradation curves are shown in Figure 2. Both the simple first-order kinetic model and the availability-adjusted first-order kinetic model were used to fit the experimental data. OTC degradation in chicken manure seemed to follow the availability-adjusted first order loss model well. The regression coefficients of the kinetic data fitting from all OTC degradations in chicken manure with the availability-adjusted loss model and simple first-order model were 0.994 and 0.912 , respectively. Therefore, the OTC degradation in manure was fitted by the availability-adjusted first-order kinetic model.

Table 1. Extraction Recovery (\% mean standard deviation) of OTC from different matrices ( $n=4$ for each matrix).

\begin{tabular}{ccccc}
\hline \multirow{2}{*}{ matrices } & \multicolumn{4}{c}{ spiked level (mg.kg $\mathrm{kg}^{-1}$ dry weight) } \\
\cline { 2 - 5 } & 3 & 6 & 10 & 15 \\
\hline Chicken manure & $83 \pm 4$ & $86 \pm 3$ & $85 \pm 5$ & $88 \pm 7$ \\
water & $93 \pm 2$ & $95 \pm 4$ & $96 \pm 4$ & $95 \pm 6$ \\
\hline
\end{tabular}



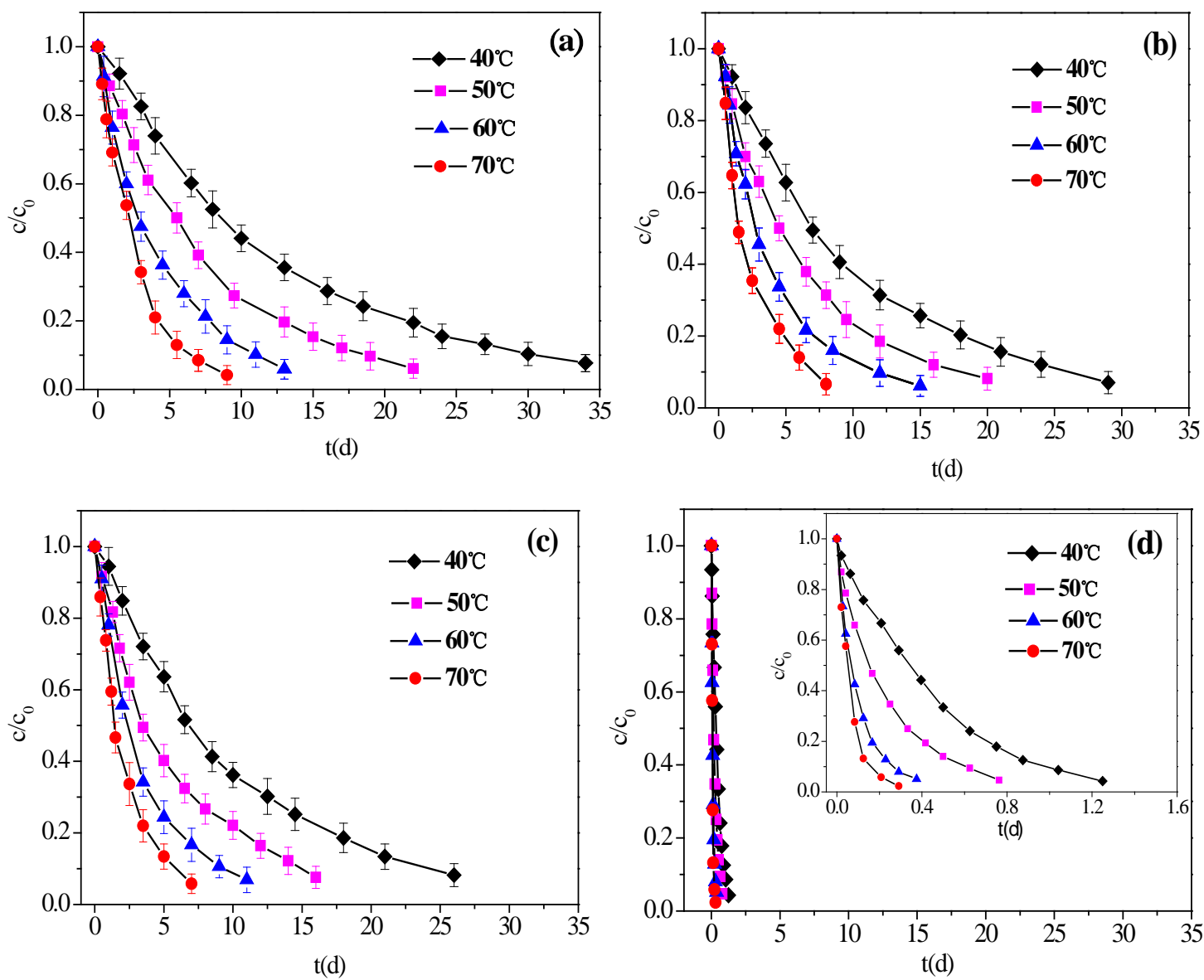

Figure 2. The degradation of OTC at different temperatures. The initial concentrations of OTC were (a) 100, (b) 25, and ((c), (d)) $10 \mathrm{mg} \cdot \mathrm{L}^{-1}$. The matrices were chicken manure ((a)-(c)) and pure water (d).

The rate constants for OTC degradation in manure varied from approximately 0.084 to $0.458 \mathrm{~d}^{-1}$, with half-lives of OTC varying from 1.56 to $8.50 \mathrm{~d}$. The OTC degradation in water is showed in Figure 2(d). Because the common contents of OTC in chicken manure are $5-20 \mathrm{mg} \cdot \mathrm{kg}^{-1}$, the initial concentrations of OTC in water was set at $10 \mathrm{mg} \cdot \mathrm{L}^{-1}$. The kinetic constants for OTC degradation in water were $2.208,3.552,8.520$, and $14.112 \mathrm{~d}^{-1}$ at $40^{\circ} \mathrm{C}, 50^{\circ} \mathrm{C}, 60^{\circ} \mathrm{C}$ and $70^{\circ} \mathrm{C}$, respectively, with half-lives varying from $0.05 \mathrm{~d}$ to $0.31 \mathrm{~d}$. From Figure 3, it can be seen that the kinetic constants of OTC degradation in water were much larger than that in manure, indicating that the degradation rate was much faster in water than in manure at the same OTC concentrations. It may be caused by desorption hysteresis. Metal ions also formed complexes with OTC; this affected the diffusion of OTC in chicken manure.

\subsection{Effect of Metal Ions on Degradation}

There are many kinds of metal ions in chicken manure, such as $\mathrm{As}^{5+}, \mathrm{Cr}^{6+}, \mathrm{Cu}^{2+}, \mathrm{Zn}^{2+}, \mathrm{Ni}^{2+}, \mathrm{Pb}^{4+}, \mathrm{Ca}^{2+}, \mathrm{Fe}^{3+}, \mathrm{Na}^{+}$, $\mathrm{Mg}^{2+}, \mathrm{Mn}^{6+}$, and so on. Some of them are present at such low concentrations that not every of them can complex with OTC. The effect of complexation on the OTC degradation was investigated because the formation of metalOTC complex may become important at higher concentrations of multivalent metal cations. Sorption-desorption hysteresis was observed by Gu [21]. The relatively strong interaction between OTC and metal ions was expected to significantly influence the reactivity, mobility and bioavailability of this antimicrobial compound in soils and subsurface environments. The release of adsorbed OTC may be hindered by the existence of apparent sorption-desorption hysteretic behavior and its bioavailability and degradation may be decreased. In this study, four metal ions $\left(\mathrm{Ca}^{2+}, \mathrm{Zn}^{2+}, \mathrm{Ni}^{2+}, \mathrm{Cu}^{2+}\right)$, which were the essential components in manure, were chosen to complex with OTC in aqueous solution. By using microwave induced plasma-atomic emission spectroscopy, the contents 


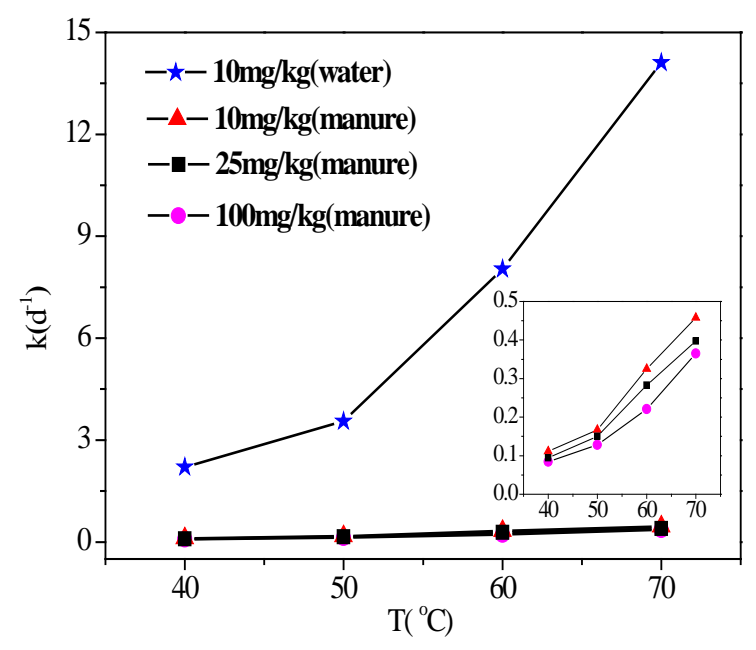

Figure 3. Dependences of kinetic constants on temperature in chicken manure and pure water.

of water soluble metal ions in chicken manure were measured as $\mathrm{Ca}^{2+} 7.24 \mathrm{~g} \cdot \mathrm{kg}^{-1}, \mathrm{Ni}^{2+} 4.17 \mathrm{mg} \cdot \mathrm{kg}^{-1}, \mathrm{Zn}^{2+} 23.33$ $\mathrm{mg} \cdot \mathrm{kg}^{-1}$, and $\mathrm{Cu}^{2+} 5.42 \mathrm{mg} \cdot \mathrm{kg}^{-1}$. The concentrations of $\mathrm{Ca}^{2+}$ in chicken manure were often in the levels of $\mathrm{g} \cdot \mathrm{kg}^{-1}$ and much larger than other three metal ions.

As shown in Figure 4, the degradation of OTC $\left(10 \mathrm{ppm}, 0.02172 \mathrm{mmol} \cdot \mathrm{L}^{-1}\right)$ in aqueous solutions was conducted in the presence of $\mathrm{Ca}^{2+}\left(7240 \mathrm{ppm}, 0.1806 \times 10^{3} \mathrm{mmol} \cdot \mathrm{L}^{-1}\right), \mathrm{Zn}^{2+}\left(23.33 \mathrm{ppm}, 0.3569 \mathrm{mmol} \cdot \mathrm{L}^{-1}\right), \mathrm{Ni}^{2+}$ (4.17 ppm, $\left.0.07104 \mathrm{mmol} \cdot \mathrm{L}^{-1}\right)$ or $/ \mathrm{and}^{\mathrm{Cu}^{2+}}\left(5.42 \mathrm{ppm}, 0.08535 \mathrm{mmol} \cdot \mathrm{L}^{-1}\right)$ at temperatures of $40^{\circ} \mathrm{C}-70^{\circ} \mathrm{C}$, where the concentrations of metal ions were the same as that found in the manure sample. At each of the tested temperatures, it was found that the presence of $\mathrm{Ca}^{2+}, \mathrm{Ni}^{2+}$ and $\mathrm{Zn}^{2+}$ decreased the degradation rate of OTC, whereas $\mathrm{Cu}^{2+}$ accelerated the degradation of OTC. Similar degradation experiments were also performed in the presence of metal ions at a low concentration $\left(0.04344 \mathrm{mmol} \cdot \mathrm{L}^{-1}\right)$. The data fitting from the degradation experiments gave the effects of temperature on the degradation rate constant of OTC $\left(10 \mathrm{ppm}, 0.02172 \mathrm{mmol} \cdot \mathrm{L}^{-1}\right)$ in aqueous solutions in the presence of metal ions at both lower and higher concentrations.

Different metal ions would bring about different effects, due to their complex stability. From the reports of Doluisio and Martin [22] and Lambs et al. [23], the stability constants were 4.5, 8.4, 10.7, 12.7 for the complexes of Ca-OTC, Zn-OTC, Ni-OTC, Cu-OTC, respectively. As shown in Figure 5(a), the kinetic constants of OTC degradation were $0.092,0.148,0.335$, and $0.588 \mathrm{~h}^{-1}$ at $40,50,60$, and $70^{\circ} \mathrm{C}$, respectively, in water in the absence of metal ions. When metal ions were added with the same load $\left(0.04344 \mathrm{mmol} \cdot \mathrm{L}^{-1}\right)$, the degradation rate constant of OTC at $40^{\circ} \mathrm{C}$ was decreased to $0.081,0.046$, and $0.022 \mathrm{~h}^{-1}$ by $\mathrm{Ca}^{2+}, \mathrm{Zn}^{2+}$ and $\mathrm{Ni}^{2+}$, respectively. The decreasing effect of these metal ions was increased in an order of $\mathrm{Ca}^{2+}<\mathrm{Zn}^{2+}<\mathrm{Ni}^{2+}$, which is the same that the order of the stability constant of the metal-OTC complexes. By comparing the corresponding curves in Figure 5(a) and Figure 5(b), it was found that the greater addition of the metal ion increased its depression effect.

Unlike the other metal ions $\left(\mathrm{Ca}^{2+}, \mathrm{Zn}^{2+}\right.$ and $\left.\mathrm{Ni}^{2+}\right)$, the addition of $\mathrm{Cu}^{2+}$ accelerated the degradation of OTC in aqueous solutions at all the tested temperatures. At the concentration of $0.04344 \mathrm{mmol} \cdot \mathrm{L}^{-1}$, the presence of $\mathrm{Cu}^{2+}$ increased the degradation rate constant of OTC to $0.120,0.189,0.393$, and $0.619 \mathrm{~h}^{-1}$ at $40^{\circ} \mathrm{C}, 50^{\circ} \mathrm{C}, 60^{\circ} \mathrm{C}$, and $70^{\circ} \mathrm{C}$, respectively. This hints that $\mathrm{Cu}^{2+}$ is a catalyst of OTC degradation.

Because of the different effects of the various metal ions, the degradation of OTC in a practical system will be determined by the combination of various metal ions. In the solution containing all the tested metal ions $\left(\mathrm{Ca}^{2+}\right.$, $\mathrm{Zn}^{2+}, \mathrm{Ni}^{2+}$, and $\mathrm{Cu}^{2+}$ ), the OTC degradation was observed to be depressed to an extent.

\section{Conclusion}

The degradation of OTC both in aqueous solution and in chicken manure was observed at the tested temperatures. The degradation of OTC in water was faster than in chicken mature. At $40^{\circ} \mathrm{C}$, more than $95 \%$ of OTC in water was degraded in 2 days, while it took about 30 days in mature. Desorption hysteresis may be one of the causes for the different degradation rate of OTC in these two matrices. Temperature and coexisted metal ions 

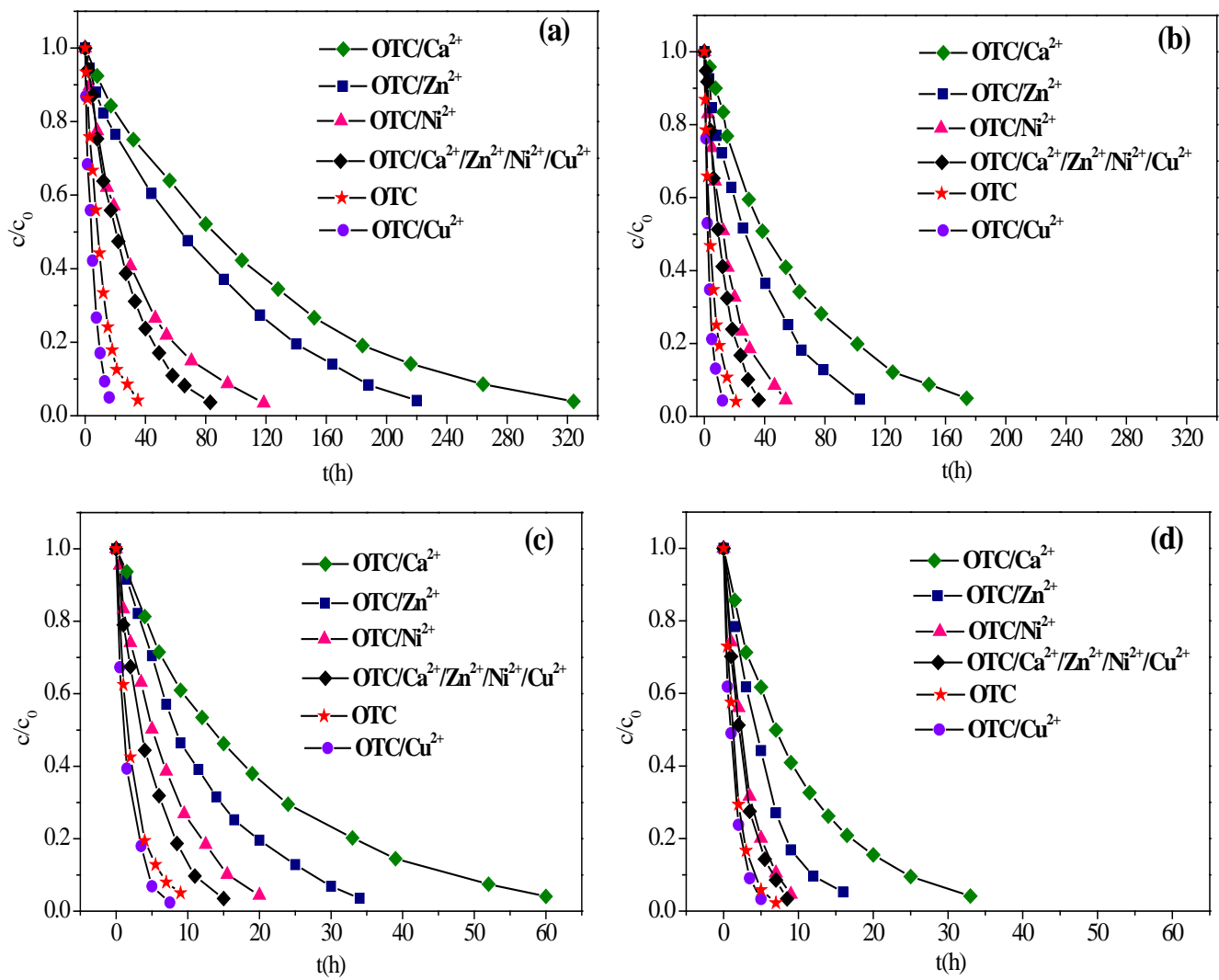

Figure 4. Degradation of OTC $\left(10 \mathrm{ppm}, 0.02172 \mathrm{mmol} \cdot \mathrm{L}^{-1}\right)$ in aqueous solutions in the presence of $\mathrm{Ca}^{2+}$ (7240 ppm, $\left.0.1806 \times 10^{3} \mathrm{mmol} \cdot \mathrm{L}^{-1}\right), \mathrm{Zn}^{2+}\left(23.33 \mathrm{ppm}, 0.3569 \mathrm{mmol} \cdot \mathrm{L}^{-1}\right), \mathrm{Ni}^{2+}(4.17 \mathrm{ppm}, 0.07104$ $\left.\mathrm{mmol} \cdot \mathrm{L}^{-1}\right)$ or/and $\mathrm{Cu}^{2+}\left(5.42 \mathrm{ppm}, 0.08535 \mathrm{mmol} \cdot \mathrm{L}^{-1}\right)$ at temperatures of (a) 40 , (b) 50 , (c) 60 , and (d) $70^{\circ} \mathrm{C}$.
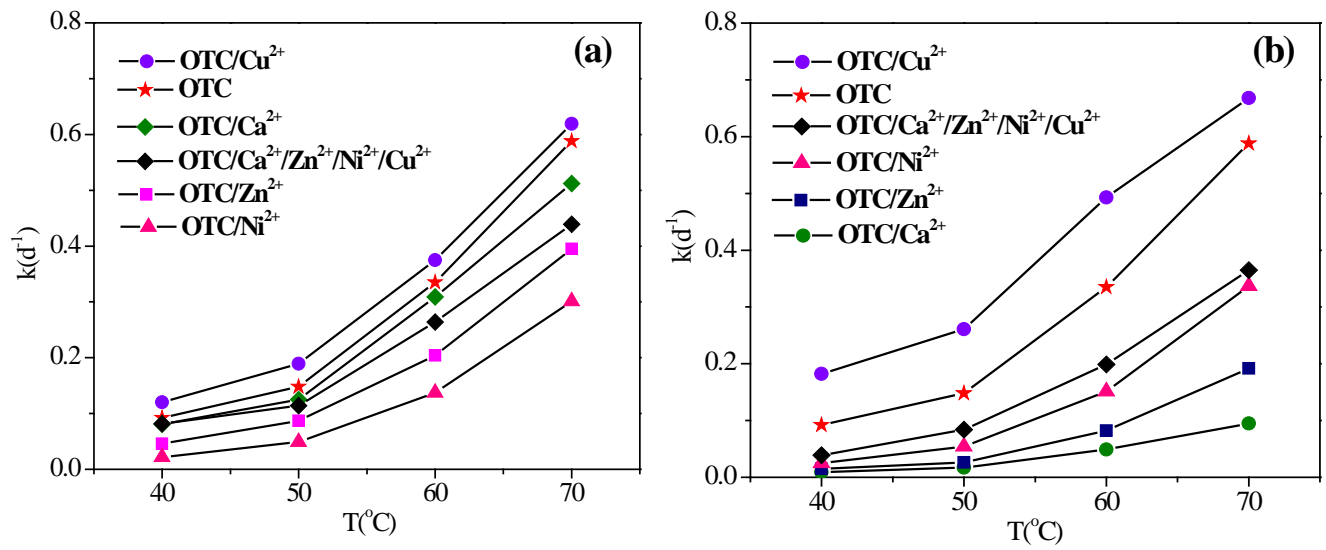

Figure 5. Effect of temperature on the degradation rate constant of OTC (10 ppm, $\left.0.02172 \mathrm{mmol} \cdot \mathrm{L}^{-1}\right)$ in aqueous solutions. (a) The added concentrations of $\mathrm{Ca}^{2+}, \mathrm{Ni}^{2+}, \mathrm{Zn}^{2+}$ or $\mathrm{Cu}^{2+}$ were $0.04344 \mathrm{mmol} \cdot \mathrm{L}^{-1}$. (b) The concentrations of metal ions in solution were $\mathrm{Ca}^{2+}\left(7240 \mathrm{ppm}, 0.1806 \times 10^{3} \mathrm{mmol} \cdot \mathrm{L}^{-1}\right), \mathrm{Zn}^{2+}(23.33$ $\left.\mathrm{ppm}, 0.3569 \mathrm{mmol} \cdot \mathrm{L}^{-1}\right), \mathrm{Ni}^{2+}\left(4.17 \mathrm{ppm}, 0.07104 \mathrm{mmol} \cdot \mathrm{L}^{-1}\right)$ and $\mathrm{Cu}^{2+}\left(5.42 \mathrm{ppm}, 0.08535 \mathrm{mmol} \cdot \mathrm{L}^{-1}\right)$, being the same as in the chicken manure correspondingly.

were confirmed to be two important factors influencing the degradation of OTC in chicken manure. By increasing the temperature to $50^{\circ} \mathrm{C}, 60^{\circ} \mathrm{C}$ and $70^{\circ} \mathrm{C}$, the required degradation time (with the degradation removal more than $95 \%$ ) was shortened to 22, 13 and 9 days, respectively. The complexation between metal ions and OTC impacted on the OTC degradation. Among the tested metal ions, the existence of most of them $\left(\mathrm{Ca}^{2+}, \mathrm{Zn}^{2+}, \mathrm{Ni}^{2+}\right)$ 
decreased the degradation rate of OTC due to the complexation effect, and one of them $\left(\mathrm{Cu}^{2+}\right)$ promoted the degradation rate of OTC due to its catalytic effect.

\section{Acknowledgements}

This work was partially supported by the National High Technology Research and Development Program of China (No. 2012AA06A304).

\section{References}

[1] Sarmah, A.K., Meyer, M.T. and Boxall, A.B.A. (2006) A Global Perspective on the Use, Sale, Exposure Pathways, Occurrence, Fate and Effects of Veterinary Antibiotics (VAs) in the Environment. Chemosphere, 65, 725-759. http://dx.doi.org/10.1016/j.chemosphere.2006.03.026

[2] Elmund, G.K., Morrison, S.M. and Grant, D.W. (1971) Role of Excreted Chlortetracycline in Modifying the Decomposition Process in Feedlot Waste. Bulletin of Environmental Contamination and Toxicology, 6, 129-132. http://dx.doi.org/10.1007/BF01540093

[3] Alcock, R.E., Sweetman, A. and Jones, K.C. (1999) Assessment of Organic Contaminant Fate in Waste Water Treatment Plants I: Selected Compounds and Physicochemical Properties. Chemosphere, 38, 2247-2262.

[4] Kumar, K., Gupta, S.C., Chander, Y. and Singh, A.K. (2005) Antibiotic Use in Agriculture and Its Impact on the Terrestrial Environment. Advances in Agronomy, 87, 1-54. http://dx.doi.org/10.1016/S0065-2113(05)87001-4

[5] Baguer, A.J., Jensen, J. and Krogh, P.H. (2000) Effects of Antibiotics Oxytetracycline and Tylosin on Soil Fauna. Chemosphere, 40, 751-757. http://dx.doi.org/10.1016/S0045-6535(99)00449-X

[6] Rynk, R. (1992) On-Farm Composting Handbook. Natural Resource, Agriculture, and Engineering Service, Ithaca, New York, 186p.

[7] Van Dijk, J. and Keukens, H.J. (2000) The Stability of Some Veterinary Drugs and Coccidiostats during Composting and Storage of Laying Hen and Broiler Faeces. In Ginkel, L.A. and Ruiter, A., Eds., Residues of Veterinary Drugs in Food, Proceedings of the EuroResidue IV Conference, Veldhoven, 8-10 May 2000, 356-360.

[8] Dolliver, H., Gupta, S. and Noll, S. (2008) Antibiotic Degradation during Manure Composting. Journal of Environmental Quality, 37, 1245-1253. http://dx.doi.org/10.2134/jeq2007.0399

[9] Kim, K.R., Owens, G., Ok, Y.S., Park, W.K., Lee, D.B. and Kwon, S.I. (2012) Decline in Extractable Antibiotics in Manure-Based Composts during Composting. Waste Management, 32, 110-116. http://dx.doi.org/10.1016/j.wasman.2011.07.026

[10] Arikan, O., Mulbry, W., Ingram, D. and Millner, P. (2009) Minimally Managed Composting of Beef Manure at the Pilot Scale: Effect of Manure Pile Construction on Pile Temperature Profiles and on the Fate of Oxytetracycline and Chlortetracycline. Bioresource Technology, 100, 4447-4453. http://dx.doi.org/10.1016/j.biortech.2008.12.063

[11] Wang, Q.Q. and Yates, S.R. (2008) Laboratory Study of Oxytetracycline Degradation Kinetics in Animal Manure and Soil. Journal of Agricultural and Food Chemistry, 56, 1683-1688. http://dx.doi.org/10.1021/jf072927p

[12] Kuhne, M., Ihnen, D., Moller, G. and Agthe, O. (2000) Stability of Tetracycline in Water and Liquid Manure. Journal of Veterinary Medicine Series A, 47, 379-384.

[13] Ratasuk, N., Boonsaner, M. and Hawker, D.W. (2012) Effect of Temperature, pH and Illumination on Abiotic Degradation of Oxytetracycline in Sterilized Swine Manure. Journal of Environmental Science and Health, Part A, 47, 16871694. http://dx.doi.org/10.1080/10934529.2012.687274

[14] Arikan, O.A., Mulbry, W. and Rice, C. (2009) Management of Antibiotic Residues from Agricultural Sources: Use of Composting to Reduce Chlortetracycline Residues in Beef Manure from Treated Animals. Journal of Hazardous Materials, 164, 483-489. http://dx.doi.org/10.1016/j.jhazmat.2008.08.019

[15] Rawat, S. and Johri, B.N. (2013) Role of Thermophilic Microflora in Composting. In: Satyanarayana, T., Littlechild, J. and Kawarabayasi, Y., Eds., Thermophilic Microbes in Environmental and Industrial Biotechnology, Springer Netherlands, Dordrecht, 137-169. http://dx.doi.org/10.1007/978-94-007-5899-5_5

[16] Kümmerer, K. (2009) Antibiotics in the Aquatic Environment-A Review: Part I. Chemosphere, 75, 417-434.

[17] Chadwick, D.R. and Chen, S. (2002) Manures. In: Haygarth, P.M. and Jarvis, S.C., Eds., Agriculture, Hydrology and Water Quality, CABI, Wallington, 57-82.

[18] Arikan, O.A., Sikora, L.J., Mulbry, W., Khan, S.U. and Foster, G.D. (2007) Composting Rapidly Reduces Levels of Extractable Oxytetracycline in Manure from Therapeutically Treated Beef Calves. Bioresource Technology, 98, 169176. http://dx.doi.org/10.1016/j.biortech.2005.10.041

[19] Wu, X., Wei, Y., Zheng, J., Zhao, X. and Zhong, W. (2011) The Behavior of Tetracyclines and Their Degradation 
Products during Swine Manure Composting. Bioresource Technology, 102, 5924-5931. http://dx.doi.org/10.1016/j.biortech.2011.03.007

[20] Kumar, K.C., Gupta, S., Chander, Y. and Singh, A.K. (2005) Antibiotic Use in Agriculture and Its Impact on the Terrestrial Environment. Advances in Agronomy, 87, 1-54. http://dx.doi.org/10.1016/S0065-2113(05)87001-4

[21] Gu, C., Karthikeyan, K.G., Sibley, S.D. and Pedersen, J.A. (2007) Complexation of the Antibiotic Tetracycline with Humic Acid. Chemosphere, 66, 1494-1501. http://dx.doi.org/10.1016/j.chemosphere.2006.08.028

[22] Doluisio, J.T. and Martin, A.N. (1963) Metal Complexation of the Tetracycline Hydrochlorides. Journal of Medical Chemistry, 6, 16-20. http://dx.doi.org/10.1021/jm00337a003

[23] Lambs, L., Decock-Le Reverend, B., Kozlowski, H. and Berthon, G. (1988) Metal Ion-Tetracycline Interactions in Biological Fluids. 9. Circular Dichroism Spectra of Calcium and Magnesium Complexes with Tetracycline, Oxytetracycline, Doxycycline, and Chlortetracycline and Discussion of Their Binding Modes. Inorganic Chemistry, 27, 3001-3012. http://dx.doi.org/10.1021/ic00290a022 